\title{
ANÁLISE DO DISCURSO DE FAMÍLIAS DE CRIANÇAS IDENTIFICADAS COMO GAGAS: MITOS E SILENCIAMENTOS
}

\author{
NADIA PEREIRA DA SILVA GONÇALVES DE AZEVEDO ${ }^{1}$; \\ MARIA DO CARMO GOMES PEREIRA CAVALCANTI ${ }^{2}$
}

\author{
Universidade Católica de Pernambuco \\ Centro de Ciências Biológicas e da Saúde \\ Rua do Príncipe, 526 - Boa Vista - 50050-900 - Recife, PE - Brasil \\ $\underline{\text { nadiaazevedo@gmail.com , carmingpc@yahoo.com.br }}$
}

\begin{abstract}
RESUMO. Este trabalho lança um outro olhar relativo aos estudos da gagueira, a ótica linguístico-discursiva. As propostas terapêuticas mais divulgadas se dividem em dois paradigmas: o centrado no sintoma e o centrado no sujeito. Pesquisadores filiados ao primeiro paradigma procuram marcar, no corpo, a gênese do distúrbio ou patologia, como é por muitos nomeada, negligenciando as posições discursivas, considerando conhecimento vulgar a dinâmica disfuncional da família como agente precipitador da gagueira. Este trabalho tem por escopo analisar o discurso de familiares de crianças ditas gagas no Grupo de Estudos e Atendimento à Gagueira Infantil (GEAGi) para identificar a evidência de mitos, além do silenciamento da criança, bem como descrever a mudança de Formação Discursiva no discurso da família de crianças identificadas como gagas e constatar a mudança da posição sujeito da criança a partir do discurso das famílias e participação do pesquisador no GEAGi. Este trabalho é parte da dissertação de mestrado de uma das pesquisadoras em que a $\mathrm{AD}$ foi o instrumento teórico-metodológico e se ancora no estudo da gagueira realizado por Azevedo (2000; 2006; 2013). A abordagem desta pesquisa será qualitativa e desenvolvida no GEAGi em Universidade do Recife. Utilizamos como aparato teórico-metodológico a Análise do Discurso de linha francesa (AD), fundada por Pêcheux e desenvolvida no Brasil por Orlandi e outros estudiosos, articulando-a a estudos de alguns especialistas em gagueira como Azevedo, Freire, entre outros. O método utilizado será o discursivo a partir do trabalho sistemático com escuta familiar e, como procedimento, recortes dos discursos de dois sujeitos sobre crianças ditas gagas, constituídos longitudinalmente, gravados em áudio e transcritos literalmente para posterior análise. Apoiando as análises no interdiscurso, identificaram-se algumas formações discursivas corporeificadas no discurso dos sujeitos em estudo. A análise discursiva apontou para uma mudança de formação
\end{abstract}

\footnotetext{
${ }^{1}$ Doutora em Letras e Linguística pela UFPB, Professora e Pesquisadora do PPGCL da UNICAP (Programa de Pós-Graduação em Ciências da Linguagem da Universidade Católica de Pernambuco).

${ }^{2}$ Mestranda do Curso de Ciências da Linguagem da UNICAP (Universidade Católica de Pernambuco), bolsista FACEPE e Professora da Rede Municipal do Recife.
} 
discursiva de fluência ideal para fluência não linear e o caminho linguísticodiscursivo como possibilidade terapêutica.

Palavras-chave: família; formação discursiva; gagueira; Análise de Discurso.

\begin{abstract}
This work takes a different view on the stuttering studies, linguistic and discursive view. The most widespread therapeutic approaches are divided into two paradigms: the symptom-centered and focused on the subject. Researchers affiliated with the first paradigm seek to distinguish, in the body, the genesis of the disorder or pathology, as for many named, overlooking the discursive positions, considering common knowledge dysfunctional family dynamics as precipitator agent to stuttering. This work has the scope to analyze the family speech of children said stutters in Child Stuttering Studies and Assistance Group (Grupo de Estudos e Atendimento à Gagueira Infantil - GEAGi) to identify evidence of myths, in addition to the child silencing, and to describe the change of Discursive Formation in the family speech of children identified as stutterers and note the change in subject position of the child from the discourse of families and participation of the researcher in GEAGI. The approach of this research is qualitative and developed in GEAGI in University of Recife. We used as a methodological and theoretical apparatus the French Analysis of Speech, outlined by Pêcheux and developed in Brazil by Orlandi and other scholars, linking the studies of some stuttering experts as Azevedo, Freire, among others. The method used is the discursive based on the systematic work of family listening and, as procedure, two fragments of families discourse formed longitudinally recorded in audio and transcribed literally for further analysis. Supporting the analysis in interdiscursivity, it was identified some embodied discursive formations in the speech of the subjects under study. The discursive analysis indicated a change of discursive formation of ideal fluency for nonlinear fluency and the linguistic-discursive approach as a therapeutic possibility.
\end{abstract}

Keywords: family; discursive formation; stuttering; Discursive Analysis.

\title{
Estado da Arte
}

A gagueira é um assunto que suscita polêmica entre diferentes profissionais, seja em relação à sua etiologia ou melhor conduta terapêutica. Apesar de algumas perspectivas confluírem em alguns aspectos permanece uma multicausalidade relacionada a sua gênese, ora predominando uma proposta terapêutica centrada no sintoma, ora, no sujeito. Essas abordagens fiéis à fundamentação teórica em que se ancoram, deixam escapar a linguagem e, consequentemente, o sujeito, e convergindo com os estudos de Azevedo (2000, p. 8, 2006, 2015); Barros (2004) sabemos que sujeito e linguagem se constituem mutuamente. Essa reflexão interrogou as pesquisadoras que, concordando com alguns estudiosos, passaram a compreender a gagueira pela ótica linguístico-discursiva com possibilidade terapêutica nessa mesma perspectiva.

Acredita-se que não se pode recortar a gagueira do sujeito, ou seja, estudá-la separadamente, já que o sujeito é constituído na/pela linguagem, inserido em uma 
sociedade hierarquizada atravessada por ideologias que interpelam indivíduos em sujeitos. A ideologia produz efeito de evidência do que é correto, aceitável. Interessa estudar a gagueira tendo como aporte teórico- metodológico a AD de linha francesa delineada por Pêcheux e desenvolvida no Brasil por Orlandi e outros estudiosos; porque de todas as áreas que dialogam com a fonoaudiologia, a AD consegue fundamentar o fazer clínico incluindo o sujeito e a linguagem. Nesta direção, este trabalho afasta-se de perspectivas teóricas que identificam a gagueira como algo que se dá a ver no corpo e na fala, assumimos um posicionamento de circunscrever o discurso como lugar e origem de apresentação da gagueira (AZEVEDO, 2000, p. 42, 2006, 2015).

Adota-se AD porque essa trabalha com a língua atuando no mundo, com distintas maneiras de significar, considerando a produção de sentidos como parte da vida dos sujeitos, permitindo a materialização da ideologia no discurso. A ideologia, por sua vez, produz no sujeito a ilusão de transparência que o sentido é único, quando esse pode derivar para outro. A AD constitui-se no entremeio de três regiões do conhecimento: o Materialismo Histórico, a Linguística e a Psicanálise.

O materialismo histórico, como teoria das formações sociais e suas transformações, compreendida neste aspecto a teoria das ideologias; a linguística, como teoria dos mecanismos sintáticos e dos processos de enunciação e a teoria do discurso, como aquela da determinação histórica dos processos semânticos. Estas três regiões são, de certa forma, articuladas por uma teoria da subjetividade de natureza psicanalítica como afirma Pêcheux (2014).

A AD trabalha com a língua enquanto estrutura simbólica que abarca o nãosistematizado, ou seja, a falha; com o sujeito constituído pela falta, efeito de linguagem e ao mesmo tempo sujeito do desejo e da ideologia; e com o discurso, materialidade linguística e histórica que imiscui a exterioridade como parte constituinte (FERREIRA, 2007). Adotamos a AD porque essa percebe a linguagem como uma prática simbólica que se relaciona com as práticas sociais em geral, como afirma Orlandi (2012).

Considerando os pressupostos teóricos da $\mathrm{AD}$ que compreendem o sujeito assujeitado à língua, à uma formação discursiva ideológica, percebe-se o sujeito ocupando diferentes posições-sujeito, conforme as distintas condições de produção. Isso é importante para uma melhor compreensão da prática discursiva dos sujeitos.

Pretendemos, através deste trabalho, analisar recortes discursivos de dois sujeitos sobre crianças ditas gagas no Grupo de Estudos e Atendimento à Gagueira Infantil (GEAGi) para identificar a evidência de mitos, além do silenciamento da criança. Tencionamos também descrever a mudança de Formação Discursiva no discurso da família de crianças identificadas como gagas e constatar a mudança da posição sujeito da criança a partir do discurso das famílias e participação do pesquisador no GEAGi. Para isso, operaremos 10 recortes discursivos e como procedimento teórico-metodológico, a Análise de Discurso de linha francesa (AD), fundada por Pêcheux e desenvolvida no Brasil por Orlandi e outros estudiosos. Iniciaremos abordando o Estado da Arte sobre a gagueira, em seguida a importância da presença da família no espaço fonoaudiológico; logo após delinearemos o caminho metodológico do trabalho, posteriormente a ótica linguístico-discursiva como possibilidade terapêutica, em seguida a análise de recortes discursivos e, por fim, teceremos nossas considerações finais. 


\section{A importância da presença da família no espaço terapêutico}

Considera-se a família o espaço de socialização primária seminal para a aquisição e desenvolvimento da linguagem, umbral para a vida social, mas que, pautada em relações de força e numa dinâmica disfuncional, instauram sentidos negativos que reverberam nas situações de fala.

No processo de aquisição da linguagem, há pais que interpretam seus filhos e eles adquirem a linguagem, configurando-se falantes ideais. E quando eles não apresentam uma fluência ideal? E quando gaguejam? Ao contrário de estudos veiculados sobre a gagueira, que compreendem o sujeito gago como indivíduo centrado, detentor de uma única identidade, esses sujeitos permanecem em suas posições de gago, controlando sua gagueira. São sujeitos que apresentam previamente a certeza que gaguejarão. Propomos uma nova concepção de sujeito, o sujeito da AD. O sujeito atravessado pela ideologia e assujeitado à língua, o efeito sujeito. Este trabalho distancia-se de teorias que identificam a gagueira apenas ao corpo, à fala Assume-se uma posição de circunscrever a gagueira ao espaço discursivo, como origem, lugar de manifestação e manutenção da gagueira. (AZEVEDO, 2013, p.146-147).

Azevedo e Freire (2001); Azevedo (2000, 2006) convocam a família para a compreensão do funcionamento discursivo gaguejante. Asseveram que todos nós estamos sujeitos à ordem da língua, mas não nos submetemos a sua forma e sim ao sentido do que falamos. Isso acontece inicialmente no processo de socialização primária, na família. Com o sujeito gago acontece o contrário.

No seu processo de aquisição e desenvolvimento da linguagem, a criança vai adquirindo um vasto sistema lexical e a dificuldade em selecionar palavras no seu repertório linguístico (eixo metafórico) a conduz à disfluência. É natural a criança gaguejar. A família, desconhecendo este processo inerente a aquisição e expansão da linguagem, então, quando diz "Fale direito! Fale devagar! Respire antes de falar", está exigindo uma postura linguística da criança incompatível para aquele momento. A disfluência é constituinte do sujeito e permanecerá durante sua vida, visto que o conceito de fluência é ideal. A criança constitrui-se gaga na infância, em suas relações discursivas, conforme atestam Azevedo (2000, 2006, 2013, 2015); Azevedo e Freire (2001), Cavalcanti (2011) e Petrusk (2013).

Os processos de organização interna da linguagem dividem-se nos eixos metafórico e metonímico. No processo de aquisição, expansão da linguagem, a criança, frente à escolha de significantes em sua cadeia linguística, não encontra condições de seleção/substituição no eixo metafórico e, enquanto realiza esse processamento, desliza no eixo metonímico, repetindo sílabas, palavras, prolongando fonemas (AZEVEDO; FREIRE, 2001; AZEVEDO, 2006).

A tensão natural existente entre língua e fala para o sujeito gago torna-se uma desarmonia que não só engendra a gagueira, mas também a reação negativa, o efeito de estranhamento do outro que, recusando sentido à disfluência, atribui-lhe o sentido patológico. Dessa forma, a interpretação do ouvinte perde o caráter de provisoriedade no aprisionamento de sentidos configurando-se como vaticínio (AZEVEDO, 2000; AZEVEDO; FREIRE (2001). Há um investimento da interpretação do outro sobre a fala da criança e quando essa escapa ao padrão do que é esperado ocorre um estranhamento. 
O efeito do ouvinte na criança pode deslocá-la a recusar-se a falar ou utilizar diferentes estratégias para que a gagueira natural se oculte, o que ao contrário reforça sua presença. Utiliza estratégias não discursivas como bater os pés, mãos, piscar os olhos canalizando a tensão trazida pela possibilidade discursiva para outro órgão, ou substitui palavras por outras que considera mais fáceis, ou seja, ou é silenciada pelas condições de produção ou aliena-se no eixo da língua ficando o sentido à deriva. Quando o adulto passa a conferir uma interpretação a fala da criança não se preocupando com a forma, mas com o conteúdo da mensagem, não fiscalizando seu dizer, daí ela passará a posição de interlocutora (AZEVEDO, 2000, 2006; AZEVEDO; FREIRE, 2001).

Considera-se a família inextricavelmente implicada com o que é manifesto e latente na criança, pois é no cerne dessa o primeiro contato da criança com condições de produção que a constituirão enquanto sujeito de seu dizer.

\section{Caminhos metodológicos para um novo olhar sobre a participação da família no processo terapêutico}

Este trabalho é parte da dissertação de mestrado da primeira autora em que a AD foi o instrumento teórico-metodológico. Conduzimos a pesquisa com abordagem qualitativa da produção discursiva de duas famílias com filhos diagnosticados como gagos, em processo de terapia fonoaudiológica no Grupo de Estudos e Atendimento à Gagueira Infantil (GEAGi), situado no $7^{\circ}$ andar do bloco do mestrado na UNICAP, Recife. O método utilizado neste estudo foi o discursivo e o procedimento foi a análise dos funcionamentos discursivos de recortes discursivos de dois sujeitos que são familiares de crianças ditas gagas, operando recortes de textos constituídos longitudinalmente, que versam sobre o mesmo tema a fim de caracterizar as FD. As sessões com os dois sujeitos foram realizadas no período de março de 2014 até novembro de 2015, com dois períodos de férias anuais. Aproximadamente 36 sessões com as famílias foram audiogravadas com a autorização dos participantes e transcritas literalmente para o computador, obedecendo à fala de cada responsável. Coletamos dados referentes às sessões audiogravadas com duração de uma hora quinzenalmente, num período compreendido em dezessete meses.

Quanto às considerações éticas, foram realizadas observações das sessões de terapia em grupo (GEAGi) das crianças e a análise discursiva das famílias das crianças em situação de terapia fonoaudiológica. Nesse sentido, foi apresentado a cada família o Termo de Consentimento Livre e Esclarecido (TCLE), com base na resolução 466/12 do Conselho Nacional de Ética em Pesquisa (CONEP), para participação nos estudos (Anexo I). A constituição do corpus foi realizada a partir da observação e registro com gravador das reuniões quinzenais realizadas com as famílias, sob coordenação da $\operatorname{Prof}^{\mathbf{a}} \operatorname{Dr}^{\mathbf{a}}$ Nadia Pereira Gonçalves de Azevedo, pesquisadora principal deste projeto, com a participação de mestrandos em Ciências da Linguagem, fonoaudiólogos e alunos de graduação em Fonoaudiologia e Letras da UNICAP. Ressalta-se, que a privacidade do sujeito que optou por participar da pesquisa foi completamente garantida, visto que recebeu uma denominação alfabética aleatória. 


\section{A ótica linguístico-discursiva para compreensão dos discursos das famílias}

De acordo com Orlandi (2013), o funcionamento da linguagem se ancora na tensão entre os processos parafrásticos e polissêmicos. Os processos parafrásticos se referem a algo que em todo dizer se mantém, às diferentes formulações do mesmo, à estabilização. Na polissemia, há o equívoco, o deslocamento, a ruptura de processos de significação. É nesta tensão entre a paráfrase e a polissemia, entre o mesmo e o diferente que os sujeitos e os sentidos se movimentam, se significam. Estes processos são bem relevantes para o olhar linguístico-discursivo.

A fala e a escuta do sujeito são determinadas por um fundo duplo, o discurso inconsciente (PÊCHEUX, 2008). O indivíduo é interpelado em sujeito pela ideologia, o que produz o apagamento necessário ao sujeito de ter um interior determinado pelo exterior, origem do que diz, causa de si. A ideologia cria a ilusão do sujeito totalmente consciente, autor de seus atos, fornecendo a cada um sua "realidade", enquanto sistema de evidências, significações percebidas, aceitas, experimentadas. A ideologia e o inconsciente constituem o sujeito dissimulando sua existência no interior de seu próprio funcionamento produzindo um efeito de evidência subjetiva (PÊCHEUX, 2009).

De acordo com Pêcheux (2009), as ideologias não são feitas de ideias, mas de práticas e não há sujeito que não as tenha. É ela que possibilita evidências pelas quais "todo mundo sabe" o que é um patrão, um operário, que faz com que uma palavra ou enunciado queiram dizer o que efetivamente dizem. O fato de não existir sentido sem interpretação, corrobora a presença da ideologia, que é constitutiva dos sujeitos e dos sentidos. O indivíduo é interpelado em sujeito pela ideologia para que, dessa forma, produza-se o dizer. A linguagem, o discurso, o sentido, os sujeitos são incompletos. Constituem-se no movimento, na falta e esta falta também é o lugar do possível (ORLANDI, 2013). O mesmo acontece com o sujeito gago. Interpelado pela ideologia da fala cem por cento fluente, que aliás não existe, ignora a opacidade, a disfluência como constitutiva da linguagem e passa a perseguir uma fala linear, perfeita.

O sujeito gago constrói sua identidade de gago pelas práticas discursivas que mantém com o outro, que também o faz ocupar um lugar social ou ter dele uma representação como menos competente, menos capaz, impossibilitado de realizar determinadas atividades, figura estranha, que provoca risos, o "bobo da corte" e assim foi por muito tempo veiculado pela mídia.

$\mathrm{O}$ sujeito, enquanto fonte e origem do dizer (esquecimento $\mathrm{n}^{\mathrm{o}} 1$ ), produz a cristalização de um sentido, um lugar social, uma identidade (GRIGOLLETO; DE NARDI, 2013). O sujeito gago em suas formações imaginárias antecipa que o interlocutor espera dele uma fala perfeita, que ele acredita que nunca terá tendo em vista sua história de vida marcada por situações discursivas sofridas devido à fala gaguejada. Ele acredita que nunca se deslocará da posição de sujeito gago, pois ignora que não possui problema fonoarticulatório. Palavras que considera difíceis ou impossíveis de serem ditas em determinadas condições de produção, em outras consegue produzir facilmente. É importante ressaltar que a família produz um discurso autoritário, solicitando da fala da criança algo que está além de sua capacidade de realização (AZEVEDO, 2000, 2006, 2013). 
Perceber a gagueira sob a perspectiva linguística discursiva, tomando como orientação teórica a $\mathrm{AD}$, permite vislumbrar o intricado nó, para além do orgânico que contempla a família e outros espaços sociais como implicados no desencadear deste distúrbio de linguagem. Longe de contendas e de total consenso, procura-se um novo olhar que não emana do senso comum, mas que também não é mensurado por quantidade, frequência de sílabas gaguejadas, mas parte da linguística e, ao mesmo tempo, dela se afasta.

\section{O processo de atendimento às famílias fundamentado na Análise do Discurso}

As análises aqui apresentadas são referentes aos recortes discursivos extraídos de sessões realizadas com as famílias, representativas de dois momentos do processo terapêutico: $\mathrm{O}$ encontro inaugural e recortes de sessões posteriores. A partir deste trabalho, foi possível acompanhar longitudinalmente, o discurso das famílias até o processo de alta fonoaudiológica das crianças participantes do GEAGi. A coluna da direita corresponde ao recorte de um mesmo familiar e a coluna da esquerda corresponde ao recorte do terapeuta. T1 corresponde a primeira sequência discursiva, T2 a segunda sequência, e assim sucessivamente. As primeiras análises serão do discurso do sujeito nomeado por A. As análises a partir da página 10 serão de outros sujeitos que nomeamos por D.

\section{Análise da sequência discursiva do sujeito A}

T1-(...) A gente assim queria saber como é que está sendo em relação à fala (das crianças). Quem quer começar a falar?

T2- isso é muito bom, porque ela já se percebe melhor. E na escola, em relação à fala? Lapso da terapeuta.
Ela teve uma crise braba, de não conseguir falar. Ela sempre botava um ah e um ah e nera pra poder sair alguma coisa, foi esse artifício que ela arrumou, mas era muito difícil, mas agora tá bem melhor, falando direitinho sem botar um artifício qualquer pra pode falar e se sentindo segura.

Aí ela disse: - ai titia nem preciso mais ir!

Ela pensava: não fui, vou ficar mais gaga $e$ agora já está pensando em ter alta.

Na escola, só foi dificuldade mesmo com aquela professora que achava lindo né, que ria, mas quando ela foi pro outro ano, a outra professora já tinha tido aluno que tinha gagueira, ela tinha 
outra cabeça, estudou na internet pra se dar bem com a aluna., sabe acho que ela começou a ficar constrangida no início e não queria falar.

Mesmo ela gaga, ela sempre foi uma metralhadora. A gente dizia respire fundo, coisas que a gente não sabia que não podia dizer respire fundo, fale devagar, a gente usou muito esse artifício.

T2. Acho que pouco mais que 2 anos, No começo também a gente achava que bater passa tão rápido...

com uma colher de pau virgem na cabeça dela iria resolver a gagueira.

Percebemos pela fala do sujeito A, no primeiro segmento discursivo, que a criança utilizava estratégias discursivas como fala Azevedo (2000, 2001, 2006, 2013, 2015), ou truques, termo utilizado por Friedman $(2004,1994)$, para adiar ou evitar a gagueira, quando interpunha um $a h$ antes de começar a falar, pois sentia insegurança em relação a sua fala, medo de falhar ao falar. Isso demonstra que a criança previa a gagueira na cadeia de significantes, o que implica que ela estava no funcionamento subjetivo discursivo da gagueira (DAMASCENO; FRIEDMAN, 2012). Este $a h$ sempre precedente à fala da criança na tentativa de liberar uma fluência produz um efeito da presença forte do interdiscurso social de fala fluente, já que fala perfeita não pode ter rupturas.

No segundo segmento discursivo, o sujeito A já demanda a alta, que em nossa proposta, deve partir do paciente. Não só a família ressignificou o conceito de fluência, como a criança se desidentificou da posição de sujeito gago, deslocando-se para sujeito fluente, não utilizando mais estratégias discursivas e não discursivas para adiar a gagueira. Os aparelhos ideológicos do Estado, termo cunhado por Althusser (1985), como a família, a Escola, são responsáveis por transmitir a ideologia dominante; mesmo sem se dar conta disso ou pelo menos de forma parcial, como fala Pêcheux (2009), no esquecimento 2, que é em nível enunciativo. Escolhemos uma palavra ou enunciado em vez de outro conforme a FD em que estamos inscritos. $\mathrm{O}$ mesmo acontece com a fala. Queremos nos ajustar a um padrão de fala, aceito como o correto, porque o interdiscurso social prepondera e determina o intradiscurso. Prosseguindo neste segmento discursivo percebemos que de acordo com o sujeito $\mathrm{A}$, a criança acreditava que se não frequentasse o grupo a gagueira voltaria como uma relação causa/efeito circulando o sentido de uma relação sinonímica faltar ao grupo é o mesmo que retorno à gagueira.

Assim, retomando a teoria, de acordo com Pêcheux (2009), o sujeito se constitui pelo esquecimento daquilo que o determina. Na Escola, a primeira professora da criança chama a atenção dela para sua gagueira, pois ri e afirma achar linda a forma como ela fala, e sem perceber, mostra um dizer marcado ideologicamente pelo preconceito ao relacionar a gagueira a algo burlesco, que foge ao normal. Na quarta sequência discursiva, a criança em suas formações imaginárias percebe que há algo errado em sua fala, mas a professora não a situa na direção do seu erro.

A escola corrige a criança e procura enquadrá-la num padrão de um discurso não desviante. Como instância de inculcação de um discurso circular que se configura entre algumas características com repetições, definições rígidas, encadeamentos 
automatizados, conclusões exclusivas, dirigidas, como atesta Orlandi (2011), tem poder de modificar ou manter certos valores, o discurso do sujeito. A família converge com a escola em relação a um discurso autoritário, como salienta Azevedo (2000, 2006), ancorada em Orlandi $(2011,2013)$ e compartilham com o senso comum de que a disfluência é um problema e que a fluência deve ser absoluta como fala (FRIEDMAN, 2015).

A família, ao solicitar à criança que respire fundo, fale devagar, o que é visto no quarto segmento discursivo, não situa a criança na direção do seu erro, mas parece conduzi-la a identificar esse em qualquer lugar do corpo. Pela postura da família a criança em suas formações imaginárias acredita que o interlocutor não está gostando de sua fala, há algo errado com ela, mas a criança não consegue identificar onde está o erro. As instituições Escola e família outorgam dizeres e exercem poder e são elementos de grande influência no desenvolver contínuo e agravamento da gagueira. A família e a escola interpretam a disfluência, inerente ao desenvolvimento da linguagem, como gagueira, e, na tentativa de ajudá-la, solicitam que respire fundo, fale devagar, o que mostra um discurso autoritário sob a perspectiva da $\mathrm{AD}$, que não traz reversibilidade. Essa ajuda que as pessoas oferecem por acreditarem que a disfluência é um problema é o que pode tornar a experiência comunicativa desagradável (FRIEDMAN, 2015). A criança, por não compreender o lugar do erro, passa a modificar sua fala na tentativa de ocultar a gagueira, pois já prevê o erro antes que ele aconteça (AZEVEDO 2000, 2006, 2013, 2015). Dessa forma, o efeito do ouvinte na criança atualiza na enunciação desta, uma memória discursiva de incapacidade. Daí utiliza estratégias variadas frente à tensão trazida pela possibilidade discursiva. No caso desta criança, sempre interpunha um ah antes de falar e com a primeira professora chegou um momento em que se recusou a falar, engessada que estava a uma forma-sujeito que a aprisionava ao discurso da impossibilidade do dizer.

De acordo com Orlandi (2007, p. 154), "no silêncio, o sentido ecoa no sujeito". Ao silenciar, a criança estava produzindo muitos efeitos de sentido sobre o seu dizer, marcado, censurado pelo riso da professora. Ao mudar de docente, voltou ao "normal", pois, segundo o sujeito A, na sexta sequência discursiva, a criança sempre foi uma metralhadora, metáfora utilizada pelo responsável que desliza para muitos efeitos de sentido, dentre eles excrescência comunicativa, agressividade. A criança joga as palavras e o sujeito A pede, às vezes, para a criança parar de falar um pouco. O "normal" desliza facilmente para o efeito de sentido contrário, ou seja, a fala da criança era patológica, anormal, com a professora que a apontava como gaga através de risos; e com a outra professora que investia sentido a fala da criança. sem dirigir sua atenção para a forma de falar a criança voltou a expor suas ideias livremente. A segunda professora nas formações imaginárias da criança agia como sua interlocutora e não como censora de seu dizer.

$\mathrm{Na}$ terceira sequência discursiva, o advérbio agora gera um efeito de sentido de mudança na forma sujeito da criança, pois antes não tinha segurança para falar e gaguejava, agora está segura em sua capacidade de falar que acredita não ser mais necessário ir ao grupo. Existe um interdiscurso social do terapeuta como sujeito suposto saber, alguém que libertará quem demanda a queixa do problema, neste caso encaminhará a criança a uma linguagem fluente.

A demanda de alta deve partir do paciente de acordo com a nossa proposta terapêutica e foi o que aconteceu com a criança. Após dois anos de tratamento, a criança 
se sentia tão segura que não queria mais frequentar o GEAGi. O trabalho em grupo é importante, pois potencializa interações, faz circular os sujeitos suscitando o deslocamento de posições fixas que dificultam as situações comunicativas (FRIEDMAN; PASSOS, 2007).

No último segmento discursivo, percebemos o mito do uso da colher de pau como possibilidade de liberação da fala fluente e fazendo uma analogia à hereditariedade de ideias explicada por Friedman (2012), as ideias são passadas de uma geração para outra porque atuam como dotadas de vida própria que, encontrando um meio cultural favorável, podem auto reproduzir-se. A memória discursiva retoma dizeres que, mesmo sem o sujeito saber de onde emanam, têm muita força nas ações do sujeito.

Após dois anos, a criança do sujeito A mudou sua posição discursiva de sujeito gago para sujeito fluente, considerando que não existe fluência absoluta, linear como atestam Friedman (1994, 2001, 2014, 2015), Friedman e Damasceno (2012); Azevedo (2000, 2006, 2013, 2015), Azevedo; Freire (2001); Scarpa (1995). Podemos constatar que a criança do sujeito A se desindentificou da posição do sujeito gago e se identificou com a posição de sujeito fluente, ou seja, distanciou-se de certos saberes que a fixavam numa posição para ela imutável. O que é anterior continuará ecoando nessa nova formasujeito da criança e do sujeito A, pelo viés do esquecimento como fala Pêcheux (2009). A família também mudou sua FD de fluência ideal, ressignificando o conceito de fluência/disfluência e ajudando a Escola a lidar com a situação. A terapeuta ressalta que pode ser um tratamento demorado, pois não depende de um fármaco que se toma e melhora como algumas concepções organicistas. Não existe remédio para a gagueira, $o$ que deve existir é respeito pelo tempo de cada um, escuta, não correção ou controle. Deixar fluir...

Analisaremos neste momento recortes discursivos do sujeito D que colocamos na coluna da direita, enquanto na coluna da esquerda estarão recortes discursivos do terapeuta. D1 é o namorado da mãe e D2, a mãe da criança.

\section{Análise da sequência discursiva dos sujeitos D1 e D2}

Tinha inclusive uma amiga de D2 (mãe) minha namorada, que indicou pra ela esperar, que isso era comum. A minha namorada até achava que ele podia piorar porque também sou gago.

Quando eu era criança, minha mãe colocava colher de pau na minha cabeça pra ver se eu melhorava, quando eu comecei a frequentar a fono, vi que a gagueira não pega nem piora outra.

$\mathrm{Tl}$ - Por isso é importante frequentar uma fonoaudióloga, que 
compreenda discursivamente o funcionamento da gagueira. É importante desmitificar algumas ideias que passam pela cabeça das pessoas como dar susto, uso da colher de pau, fazer o pinto piar dentro da boca, pois isso em nada ajuda.

Ele fazia força pra falar, chegou um momento que não queria mais falar. Ele dizia: - eu sou gago e ficava calado, apontava para não falar.

Agora nem parece como antes fala sem medo.

T2- Com 2 anos e meio, já carregando esse peso da gagueira. A criança hoje começa cedo. Antes começava com 5, 6 anos, hoje em dia vai mais cedo pra escola.

Pela experiência na clínica e no GEAGi, percebe-se que crianças cada vez mais jovens se constituem como gagas. A criança já se via como gaga ao chegar ao GEAGi, visto que com dois anos e meio, apresentava muitos bloqueios e tinha consciência de sua fala gaguejada. Sentia-se silenciada, censurada em sua fala, pois, na tentativa infrutífera de falar bem e não se mostrar gaga, fazia esforço, tensionando músculos e órgãos responsáveis pela sinergia na execução da fala. Na segunda sequência discursiva do sujeito D1, ele fala que o sujeito D2 resolveu esperar, o que evidencia a ideia do senso comum em que não se entende a gagueira como processo inerente ao desenvolvimento da linguagem, mas como um desvio que pode desaparecer em determinada fase na infância.

O sujeito D1 é gago e já possuía alguns mitos desfeitos, como bater com a colher de pau virgem sobre a cabeça de quem gagueja para cessar a gagueira, por ter também já frequentado um fonoaudiólogo. É interessante assinalar que de acordo com Azevedo; Freire (2001); Azevedo (2000, 2006), A criança do sujeito D pode ter percebido uma disfluência maior em sua fala, pelas condições de produção em que transitou, onde sempre ocorre um jogo de relações de força.

No segundo segmento discursivo do sujeito D1, observa-se que o sujeito D2 enquadra a gagueira como uma doença, que com a convivência pode passar para o outro e ficava ansiosa pelo padrasto do filho ser gago. Isso decorre de uma memória discursiva marcada por um discurso médico positivista que encapsula a gagueira a um problema orgânico. Com a convivência no grupo este mito foi desfeito. Percebemos no discurso da mãe a hereditariedade de ideias. A gagueira não tem um traço de hereditariedade e sim a disfluência conforme afirma Friedman (2012). Essa hereditariedade de ideias se refere à

\footnotetext{
${ }^{3}$ Há também, no imaginário de alguns sujeitos, mitos sedimentados socialmente, como o de que a gagueira pega, como se fosse uma doença; que bater uma colher de pau virgem na cabeça da criança sem ela perceber, com o susto cessará a gagueira. De acordo com Azevedo (2000) e Merlo; Silva (2015) além destes mitos existe ainda a crença que o nervosismo, a insegurança, a ansiedade causam a gagueira o que é desconstruído nas sessões terapêuticas.
} 
reação social constante, imperativa de interpretar a disfluência como gagueira. A criança do sujeito D não contraiu uma gagueira, pois essa não é uma doença, mas, pode ter se tornado gaga em função do modo de interlocução que se estabeleceu em sua família, das condições de produção vivenciadas pela criança.

Na terceira sequência discursiva do sujeito D1, evidencia-se que a criança, não se situando em relação ao seu erro, preferia calar-se para não descortinar sua gagueira. $\mathrm{O}$ silêncio da criança produz muitos sentidos, como medo, vergonha, incapacidade de ser sujeito de seu dizer.

No terceiro segmento discursivo, o sujeito D2 afirma que a criança fazia força para falar, pois já tinha uma imagem estigmatizada de falante característica inerente à gagueira sofrimento (FRIEDMAN, 1994). O esforço com o corpo, de acordo com Friedman (2015), é tentar corrigir um erro para não decepcionar pessoas que, para o sujeito que gagueja, são significativas. Preso à forma de falar e querendo controlar o que é automático, o sentido fica à deriva. Ao ingressar no GEAGi e compartilhar com os colegas a mesma dificuldade, a criança começou a soltar a fala, interagir, desprendendose do eixo da língua.

O advérbio agora marca um momento em que a criança se encontra inscrita em uma forma sujeito de fluência não linear, aceitou o momento de gagueira, como algo natural e que não se cala por isso, mas segue em frente, assumindo seu momento de tensão como parte de seu modo de ser fluente. A criança mudou sua posição sujeito gago para sujeito fluente, não se assujeitando mais à forma de falar.

O trabalho em grupo criou vínculos tanto para a criança quanto para os sujeitos D1 e D2 e foi capaz de colocar em funcionamento processos de identificação, oposição, aliança entre outros. O trabalho em grupo possibilita ao terapeuta intervir tanto em nível individual quanto no coletivo promovendo deslocamento de posições fixas (FRIEDMAN; PASSOS, 2007). A criança, o sujeito D1, bem como o sujeito D2, começaram a perceber o sujeito enquanto posição e fragmentaram cada um sua forma-sujeito interpelados pelos saberes que circulavam no grupo.

Como na proposta linguístico-discursiva para o atendimento a crianças e adultos com gagueira, iniciada em 2001 por Azevedo a demanda parte do paciente e a criança progrediu satisfatoriamente, os sujeitos D1, D2 e a criança deixaram de comparecer às sessões que foram frequentadas por aproximadamente um ano. Como as fronteiras das formações discursivas são porosas, os sentidos podem facilmente mover-se conforme afirma Indursky (2011). Evidencia-se mudança de posição da criança, sua desidentificação a posição-sujeito gaga. A criança falava sem colocar força, com mais frequência. Estava desinibida, autônoma, feliz com sua fluência, sabendo que todas as pessoas, apresentam, em algum momento, disfluência, que é constitutiva da fala. Os sujeitos D1 e D2 (padrasto e mãe da criança) também desidentificaram-se da FD de fluência ideal e passaram a identificar-se a FD de fluência não linear, pois agora compreendem que a fluência é constituída por disfluências e que estas são inerentes ao processo de aquisição e desenvolvimento da linguagem. 


\section{Considerações finais}

Pensar no sujeito que gagueja implica incluir o sujeito, a linguagem e a família, tendo em vista que esta última é o espaço seminal pelo qual se ingressa na ordem da cultura e das trocas simbólicas. Neste estudo, afirma-se que sob a perspectiva discursiva a gagueira é um distúrbio de linguagem diretamente relacionado às condições de produção do discurso e marcado pela previsão do erro iminente, sendo a família o umbral para o contato com essas condições de produção. Partindo dessa premissa é possível depreender a importância da família no espaço terapêutico.

Este trabalho objetivou analisar o discurso de familiares de crianças ditas gagas no Grupo de Estudos e Atendimento à Gagueira Infantil (GEAGi) para identificar a evidência de mitos, além do silenciamento da criança, bem como descrever a mudança de Formação Discursiva no recorte discursivo de dois sujeitos de crianças identificadas como gagas e constatar a mudança da posição sujeito da criança a partir do discurso das famílias e participação do pesquisador no GEAGi.

Podemos perceber, também, partir da análise dos recortes discursivos das famílias, a presença de mitos e de formações discursivas que, com a entrada no grupo foram modificados. Inicialmente, os sujeitos A e D exigiam de suas respectivas crianças uma fala perfeita, sem rupturas e não interagiam como interlocutores, mas censores. No decorrer das sessões, contraidentificaram-se dessa posição, passando a questionar a própria postura, que em nada melhorava a fala gaguejada da criança. Por fim, aceitaram a fala da criança, deixando-a livre para falar a seu modo, sem corrigi-la. Foram identificados e analisados mitos, como o susto com o uso da colher de pau virgem, que faria cessar a gagueira; a gagueira pega, é contagiosa; o nervosismo, a insegurança e ansiedade causam a gagueira. Existiram desidentificações de duas famílias às suas FD iniciais e mudanças de posição de sujeito gago para sujeito fluente. Um processo importante que colaborou para este trabalho de mudanças na forma sujeito foi a escuta sistemática das famílias pela terapeuta.

Não se considera o trabalho concluído, pois a intenção foi iluminar novos caminhos, abrir espaços para diferentes leituras, posicionamentos, questionamentos, uma vez que tudo é parte de um acontecimento significante, marcando neste trabalho o gesto de interpretação e autoria das analistas, tendo a $\mathrm{AD}$ como solo teórico para o estudo da gagueira.

\section{Referências}

AZEVEDO, N.P. da S.G. de. A gagueira sob a perspectiva linguístico-discursiva: um olhar sobre a terapia. Tese. Doutorado em Letras e Linguística, Universidade Federal da Paraíba, João Pessoa (PB), 2006.

Uma análise discursiva da gagueira: trajetórias de silenciamento e alienação na língua. Dissertação. Mestrado em Fonoaudiologia. PUC-SP, 2000. 
Uma análise discursiva de sujeitos com gagueira. Gragoatá, UFF, v. 34, 145165, Niterói, EDUFF, 2013.

Um estudo da gagueira sob a perspectiva discursiva. Revista Prolíngua, v.10, n. 1, jan.- fev., 2015. Disponível em www.periódicos.ufpb.br/index.php/prolíngua/article/ newfile/27599/14838. Acesso em jul. 2016.

AZEVEDO, N.P. da S.G. de; FREIRE, R.M. Trajetórias de silenciamento e aprisionamento na língua: o sujeito, a gagueira e o outro. Em: FRIEDMAN, S.; CUNHA, M.C. (Orgs). Gagueira e subjetividade. Possibilidades de tratamento. Porto Alegre: Artmed, 2001.

BARROS, R.C.B. de. A gagueira e sua terapêutica: estudo discursivo da escrita como possibilidade de recurso terapêutico. Dissertação. Mestrado em Linguística, UNICAMP, 2004.

CAVALCANTI, T.M.C. Análise do discurso de adultos diagnosticados como gagos em três cidades do interior do estado de Pernambuco. Dissertação. Mestrado em Ciências da Linguagem, Universidade Católica de Pernambuco, 2011.

FERNANDES, C.A. Análise do discurso: reflexões introdutórias. $2^{a}$. ed. São Carlos: Claraluz, 2008.

FERREIRA, M.C.L. Analise do discurso no Brasil: notas à sua história. Em: FERNANDES, C.A.; SANTOS, J.B.C. dos (Orgs.). Percursos da Análise do Discurso no Brasil. São Carlos: Clara Luz, 2007.

FOUCAULT, M. A arqueologia do saber. $8^{\text {a }}$. ed. Trad. Bras. Rio de Janeiro: Forense Universitária, 2014.

FRIEDMAN, Silvia. Gagueira: definição /causa /tratamento. Entrevista sobre gagueira. $\mathrm{X}$ Semana de Fonoaudiologia, SEMAFON-UNICAMP, 2012. Disponível em http://www.gagueiraesubjetividade.info/gagueira_definicao_causa_tratamento.php.

Acesso em jul. 2016.

A gagueira e o mito da fluência absoluta. Revista pátio, n. 74, ano XIX, mai. jul., 26-29, 2015.

Gagueira: origem e tratamento. $4^{\text {a }}$. ed. rev. atual. São Paulo: Summus, 2004.

Distúrbios da comunicação. Cartas a um paciente (co-autor) um processo de terapia para a gagueira. São Paulo: Educ, 1988.

A construção de personagem bom falante. São Paulo: Summus, 1994.

; PASSOS, M.C. O grupo terapêutico em fonoaudiologia: uma experiência com pessoas adultas. Em: BERBERIAN, A.P. et al. (Orgs.). Abordagens grupais em fonoaudiologia: contextos e aplicações. São Paulo: Plexus, 2007. 
GRIGOLETTO, E.; NARDI, F.S. de. Identificação, memória e figuras identitárias: a tensão entre a cristalização e o deslocamento de lugares sociais. Gragoatá, n. 34, 197213, Niterói, EDUFF, 2013. Disponível em http://revista eletrônica gragoatá.htm. Acesso em 10 jul. 2014.

LOUIS, A. Aparelhos ideológicos de estado. $3^{\text {a }}$. ed. Rio de Janeiro: Graal, 1985.

ORLANDI, E.P. Análise do discurso: princípios e procedimentos. Campinas: Pontes, 2013. Pontes, 2011.

A linguagem e seu funcionamento. As formas do discurso. $6^{a}$. ed. São Paulo: As formas do silêncio: no movimento dos sentidos. $6^{\text {a }}$. ed. Campinas: Ed. da UNICAMP, 2007.

PÊCHEUX, Michel. Por uma análise automática do discurso. Campinas: UNICAMP, 2014.

Semântica e discurso. Trad. Bras. Campinas: Editora da Unicamp, 2009.

O discurso: estrutura ou acontecimento. Trad. Bras. 5a . ed. São Paulo: Pontes, 2008.

SILVA, L.P.S. Uma análise linguístico-discursiva de sujeitos que gaguejam participantes da terapia fonoaudiológica em grupo. Dissertação. Mestrado em Ciências da Linguagem, Universidade Católica de Pernambuco, Recife, 2013.

VILAR DE MELO, Fátima. Psicanálise e Análise do Discurso: interlocuções possíveis e necessárias. Latin-American Journal of Fundamental, v. 1, ano v, nov. 2005. Disponível em www.psicopatologiafundamental.org/uploads/.../psicanalise_e analise de_discurs. Acesso em 10 jul. de 2015.

Artigo recebido em: maio de 2017.

Aprovado e revisado em: outubro de 2017.

Publicado em: novembro de 2017.

\section{Para citar este texto:}

AZEVEDO, Nadia Pereira da Silva Gonçalves de; CAVALCANTI, Maria do Carmo Gomes Pereira. Análise do Discurso de famílias de crianças identificadas como gagas: mitos e silenciamentos. Entremeios [Revista de Estudos do Discurso, on-line, www.entremeios.inf.br], Seção Estudos, Programa de Pós-Graduação em Ciências da Linguagem (PPGCL), Universidade do Vale do Sapucaí (UNIVÁS), Pouso Alegre (MG), vol. 15, p. 59-73, jul. - dez. 2017.

DOI: http://dx.doi.org/10.20337/ISSN2179-3514revistaENTREMEIOSvol15pagina59a73 